\title{
Vibration Response Characteristics Analysis and Experimental Verification of Thin-Walled Structure under Thermal-Acoustic Excitation
}

\author{
Yundong Sha, Jian Wang, and Song Xiang
}

\begin{abstract}
For the vibration response problems of aerospace thin-walled structure under thermal-acoustic excitation, combined with the theory of structural-acoustic coupling, analyze dynamic response characteristics of thin-wall rectangular plates with four edges clamped, and doing comparative verification between simulation results and test results. Meanwhile, based on different loading ways: diffusion field, progressive wave, study the stress/strain response rule of structure under the different loading combinations between SPL and temperature. Respectively analyze the structure stress/strain response's sensitivity to temperature under different acoustic loading ways. The results of the analysis will provide a reference to determine the reasonable fatigue life prediction model, and also provide an important reference for a new generation of aviation engine structure design.
\end{abstract}

Index Terms-Thin-walled structure, thermal-acoustic loads, vibration response characteristics, acoustic vibration coupling theory.

\section{INTRODUCTION}

Flame tube of aircraft engine combustor is a typical thin-walled structure bearing thermal-acoustic loadings at the same time the; thermal load, mechanical load, strong noise would make the structure produce high frequency vibration stress. Meanwhile, with high temperature and strong noise excitation, thin-walled structure will produce large deflection nonlinear vibration response [1], leading components of structure to be fatigue failure prematurely. In order to meet the requirements of the structural design of a new generation of aircraft engine, it is particularly important to carry out the research for thin-walled structure under thermal-acoustic environment.

For thermal-acoustic fatigue of aerospace thin-walled structure, foreign scholars and research institutions have already done lots of basic research for thin-wall plate and shell. Currently, for the analysis methods of structural nonlinear mainly include analytical method and numerical simulation method, including the perturbation method, the FPK equation method, equivalent linearization method (EL), reduced order models (ROM) and Galerkin method (Galerkin). C. Mei and J. M. Dhainaut [2], [3] calculated nonlinear random response of the shell structure bearing

Manuscript received December 29, 2016; revised March 1, 2017. This work was supported in part by the Aviation Basic Science Fund of China.

Yundong Sha and Jian Wang are with Liaoning Province Key Laboratory of Advanced Measurement And Test Technology of Aviation Propulsion Systems, Shenyang Aerospace University, China (e-mail: j_wang2001@sina.com).

Song Xiang is with Shenyang Aerospace University, China. thermal-acoustic excitation using FEM. NASA Langley research center and Wright - Patterson air force flight dynamics laboratory (AFFDL) of the U.S finished thermal-acoustic tests by using progressive wave tube, studying response characteristics of thin-wall structures under thermal-acoustic loadings. For thermal-acoustic loads, Langley's Rizzi [4] expounded the methods of dynamic response test and high temperature fatigue test, etc. C. F. $\mathrm{Ng}$ [5]-[7] carried out nonlinear response analysis tests of metal and composites plates with four edges clamped under thermal-acoustic loadings, by combining with a single mode equation to get the response characteristics.

In this paper, based on acoustic vibration coupling theory, finish dynamics analysis of thin-wall structure with four edges clamped; and study the influence of acoustic loading ways, the incident angle of progressive wave, sound pressure level and temperature on structural vibration response characteristics, and emphatically analyzed the stress/strain response of the structure.

\section{Simulation CALCUlation AND ANALYSis}

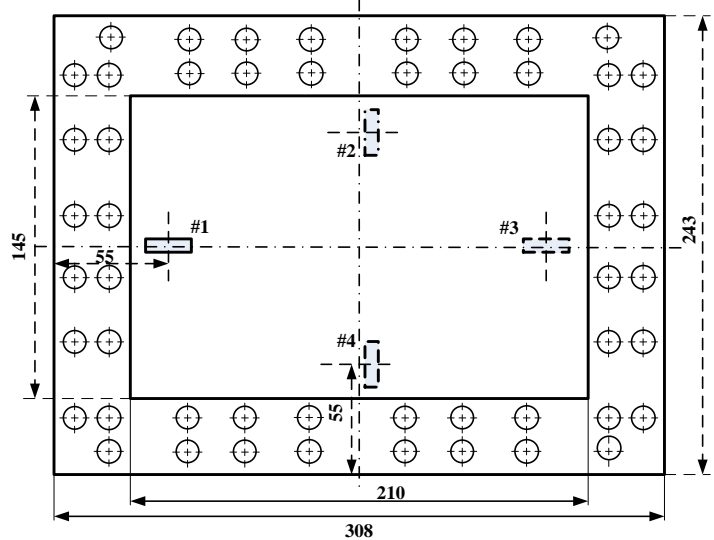

Fig. 1. The exact patch location of test piece.

TABLE I: THE LOADING WAYS OF THERMAL-ACOUSTIC

\begin{tabular}{lcc}
\hline \hline \multicolumn{2}{c}{ Types of the loads } & Loading ways \\
\hline \hline Thermal load & $50^{\circ} \mathrm{C} \sim 250^{\circ} \mathrm{C}, \Delta \mathrm{T}=50^{\circ} \mathrm{C}$ \\
\hline \multirow{3}{*}{ Acoustic load } & Frequency range & $50 \mathrm{~Hz}-1250 \mathrm{~Hz}$ \\
\cline { 2 - 3 } & The overall SPL & $142 \mathrm{~dB} \sim 160 \mathrm{Db}, \Delta \mathrm{SPL}=3 \mathrm{~dB}$ \\
\cline { 2 - 3 } & Loading ways & $\begin{array}{c}\text { Diffusion field w progressive } \\
\text { wave }\left(0^{\circ}, 45^{\circ}, 90^{\circ}\right)\end{array}$ \\
\hline \hline
\end{tabular}

Geometric model and the extraction positions of strain are shown in Fig. 1, the thickness of plate is $1.5 \mathrm{~mm}$. And the actual constraints is simplified to a calculation model with 
four edges clamped, thermal-acoustic loads are shown in Table I.

\section{A. Acoustic Loading Way Effects on Vibration Response}

Simulation calculation shows that the dangerous position of the structure at the same temperature keep be same. By extracting response results of dangerous unit finish vibration response analysis. In different acoustic loading ways, the SPL and temperatures the maximum Von Mises stress of risk unit are shown in Table II.

In $151 \mathrm{~dB}$ and $100^{\circ} \mathrm{C}$, with the increase of progressive wave incident angle (0-45-90), The Von Mises stress of structure gradually strengthens, and the results of progressive wave incident angle $0^{\circ}$ and $90^{\circ}$ are respectively the minimum maximum values of structural response. In diffusion field loading, the Von Mises stress of structure is between progressive wave loading, as shown in Fig. 2.

\section{B. The Vibration Response in Different SPL}

In $100^{\circ} \mathrm{C}$, study the structure vibration response trend under different acoustic loading ways with the change of SPL. Analysis shows that with the increase of the SPL until $148 \mathrm{~dB}$, the stress response of the structure have the approximately linear increasing trend; after $148 \mathrm{~dB}$, the thermal buckling and strong noise load makes structure presents large deflection nonlinear response, and stress response performances as a parabolic rise trend with the increase of SPL, as shown in Fig. 3.

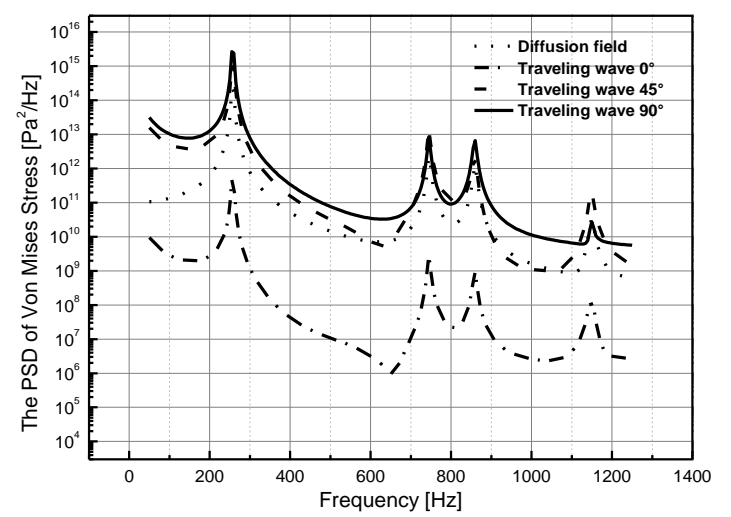

Fig. 2. The Von Mises stress PSD of the dangerous position under different acoustic loading ways.

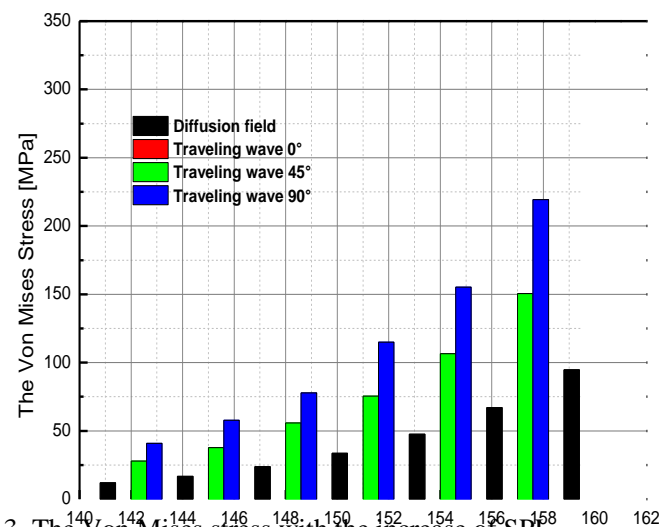

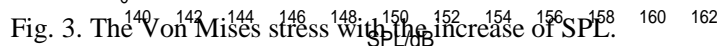

TABLE II: THE MAXIMUM Von Mises STREsS OF DANGEROUS UNIT/MPA(DIFFUSION FIELD), IN $100^{\circ} \mathrm{C}$

\begin{tabular}{|c|c|c|c|c|c|c|c|}
\hline SPL & $142 \mathrm{~dB}$ & $145 \mathrm{~dB}$ & $148 \mathrm{~dB}$ & $151 \mathrm{~dB}$ & $154 \mathrm{~dB}$ & $157 \mathrm{~dB}$ & $160 \mathrm{~dB}$ \\
\hline Diffusion field & 11.9 & 16.8 & 23.8 & 33.6 & 47.5 & 67.1 & 94.7 \\
\hline progressive wave $0^{\circ}$ & 0.5 & 0.7 & 1.1 & 1.5 & 2.1 & 3.1 & 4.1 \\
\hline progressive wave $45^{\circ}$ & 28.0 & 37.8 & 55.9 & 75.5 & 106.6 & 150.6 & 222.7 \\
\hline progressive wave $90^{\circ}$ & 40.8 & 57.7 & 77.9 & 115 & 155.3 & 219.4 & 324.2 \\
\hline
\end{tabular}

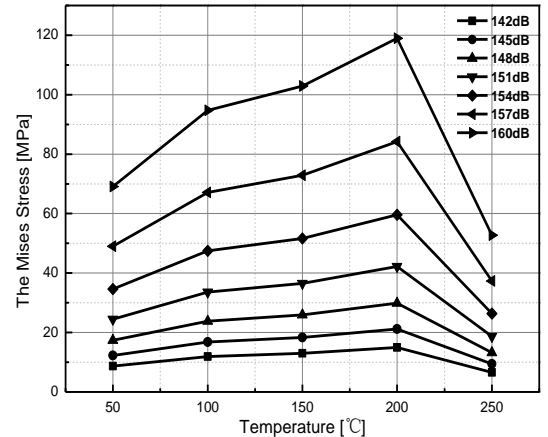

(a) The Von Mises stress

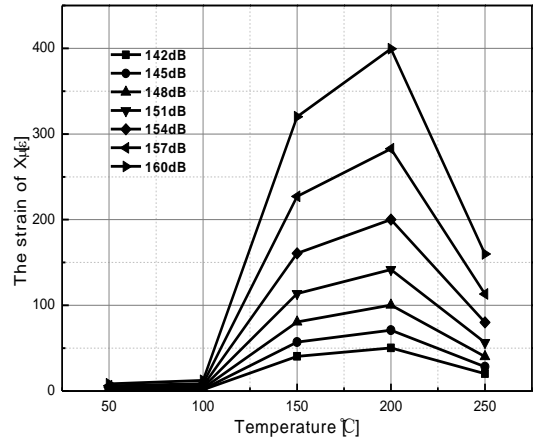

(b) the strain of $\mathrm{X}$

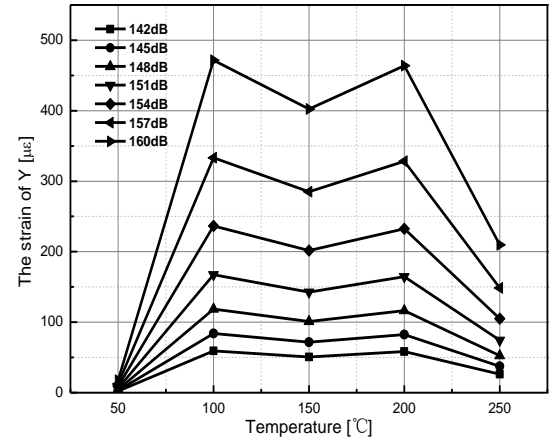

(c) the strain of $\mathrm{Y}$

Fig. 4. The change trend of dangerous unit stress/strain with the increase of temperature (Diffusion field).

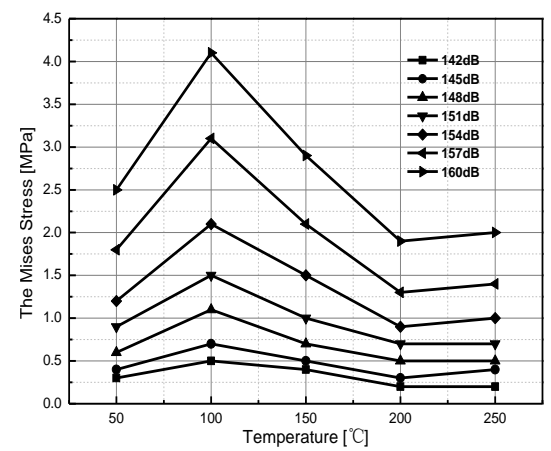

(a) The Von Mises stress

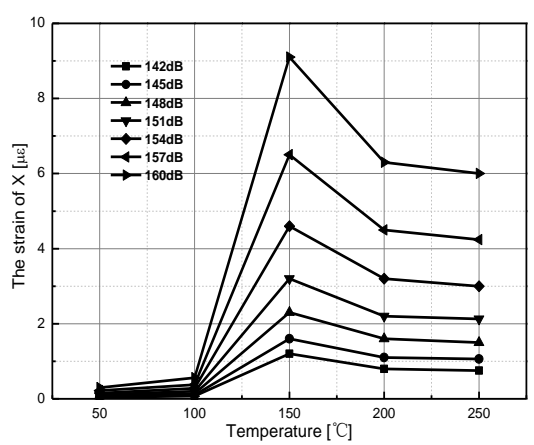

(b) the strain of $\mathrm{X}$

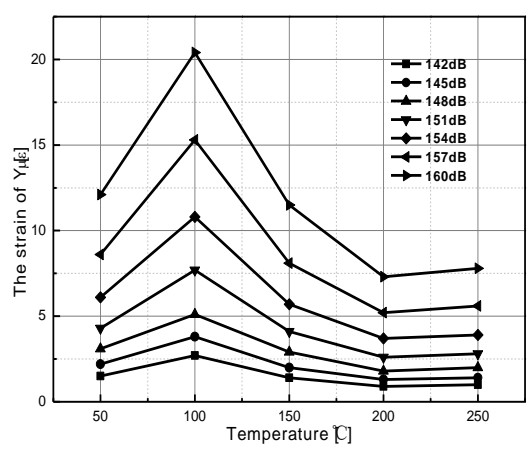

(c) the strain of $Y$

Fig. 5. The change trend of dangerous unit stress/strain with the increase of temperature (progressive wave $0^{\circ}$ ). 


\section{Vibration Response with the Change of Temperature}

For different acoustic loading ways, when the SPL is a constant, with the increase of temperature the stress of structure presents a trend of increasing first and then decreasing, but the temperatures of stress response peaks is different, and the temperatures corresponding to diffusion field and progressive wave are around $200^{\circ} \mathrm{C}, 100^{\circ} \mathrm{C}$, respectively, as shown in Fig. 4(a)-7(a). It shows that the stress of the structure vibration response has a strong sensitivity to the acoustic loading ways, especially the direction of acoustic largely affects the stress response behavior of the structure. Namely, with a certain acoustic loading direction, near the buckling, the structure will be into a snap-through area, presenting the maximum stress response, as shown in Fig. 5(a)-7(a). However, for diffusion field without a certain acoustic loading direction, while the structure enters snap-through area, jumping into the regional structure, the peak stress response has a shift, with the persistent increase of temperature to a certain value, occurring the response peak, as shown in Fig. 4(a).

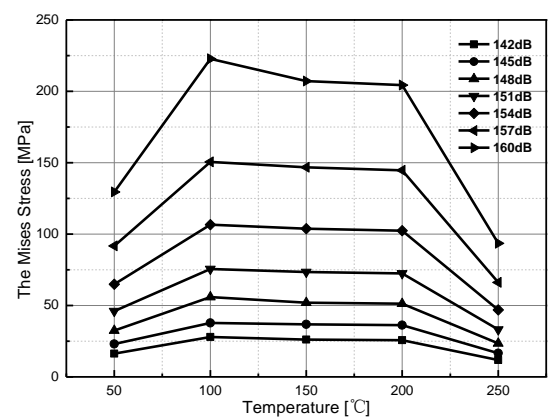

(a) The Von Mises stress

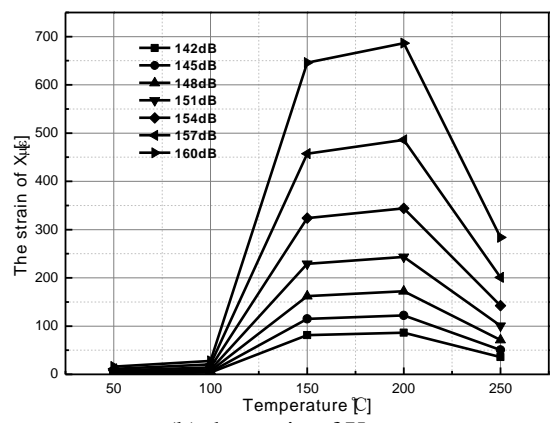

(b) the strain of $\mathrm{X}$

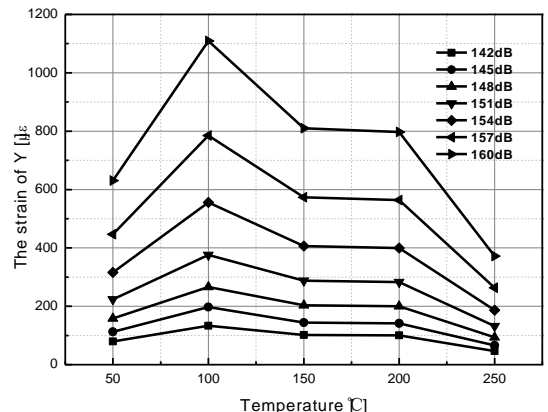

(c) the strain of $Y$

Fig. 6. The change trend of dangerous unit stress/strain with the increase of temperature (progressive wave $45^{\circ}$ ).

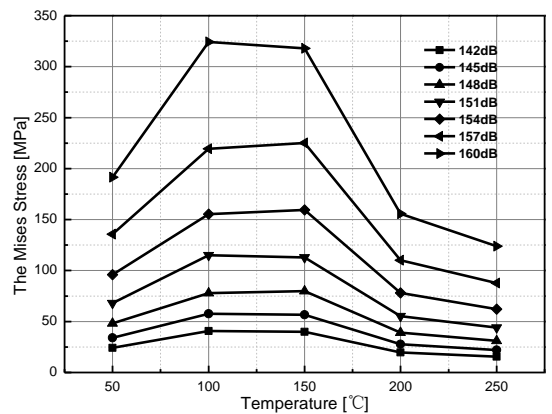

(a) The Von Mises stress

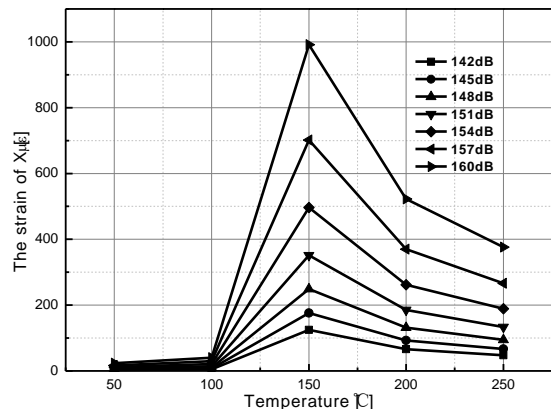

(b) the strain of $X$

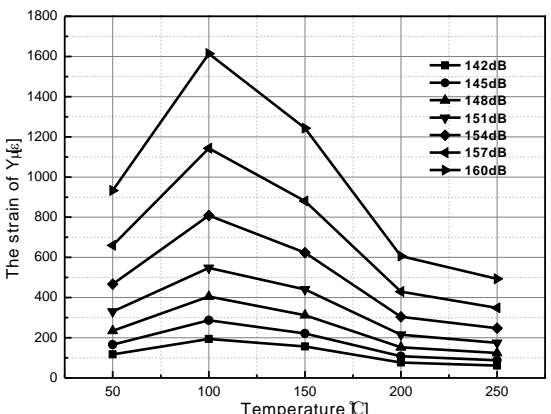

(c) the strain of $\mathrm{Y}$

Fig. 7. The change trend of dangerous unit stress/strain with the increase of temperature (progressive wave $90^{\circ}$ ).

TABLE III: THE FIRST ORDER THERMAL MODAL FREQUENCY OF TEST AND SIMULATION/Hz

\begin{tabular}{cccccc}
\hline \hline temperature & $50^{\circ} \mathrm{C}$ & $100^{\circ} \mathrm{C}$ & $150^{\circ} \mathrm{C}$ & $200^{\circ} \mathrm{C}$ & $250^{\circ} \mathrm{C}$ \\
\hline Test & 347 & 256 & 306 & 350 & 482 \\
Simulation & 347 & 257 & 307 & 350 & 481 \\
\hline \hline
\end{tabular}

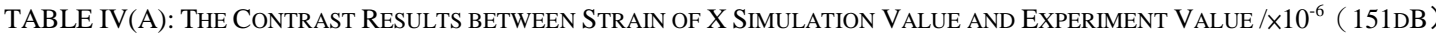

\begin{tabular}{cccccc}
\hline \hline Acoustic loading ways & Diffusion field & progressive wave $0^{\circ}$ & progressive wave $45^{\circ}$ & ${\text { progressive wave } 90^{\circ}}^{\text {Test results }^{2}}$ \\
\hline $50^{\circ} \mathrm{C}$ & 12.6 & 0.5 & 5.6 & 8.3 & 10.7 \\
$100^{\circ} \mathrm{C}$ & 19.9 & 0.9 & 9.8 & 14.9 \\
$150^{\circ} \mathrm{C}$ & 8.9 & 0.8 & 17.9 & 27.5 \\
$200^{\circ} \mathrm{C}$ & 11.6 & 0.5 & 19.8 & 15.1 \\
$250^{\circ} \mathrm{C}$ & 6.5 & 0.2 & 11.5 & 15.2 & 12.1 \\
\hline \hline
\end{tabular}

TABLE IV(B): The CONTRAST RESUltS BETWEEN STRAIN OF Y SiMUlation VALUE AND EXPERIMENT VALUE / $\times 10^{-6}$ (151DB)

\begin{tabular}{cccccc}
\hline \hline Acoustic loading ways & Diffusion field & progressive wave $0^{\circ}$ & progressive wave $45^{\circ}$ & progressive wave $90^{\circ}$ & Test results $^{\circ}$ \\
\hline $50^{\circ} \mathrm{C}$ & 4.5 & 0.2 & 8.4 & 12.4 & 29.3 \\
$100^{\circ} \mathrm{C}$ & 8.6 & 0.4 & 20.2 & 30.9 & 11.1 \\
$150^{\circ} \mathrm{C}$ & 15.4 & 0.4 & 11.6 & 8.8 \\
$200^{\circ} \mathrm{C}$ & 25.8 & 0.4 & 7.2 & 9.5 \\
$250^{\circ} \mathrm{C}$ & 14.9 & 0.6 & 14.4 & 13.1 \\
\hline \hline
\end{tabular}

For the same acoustic loading ways, the change rules of the strain of $\mathrm{X}$ and $\mathrm{Y}$ are inconsistent. The strain of $\mathrm{X}$ has a change trend of increasing first and then decreasing with the increase of temperature, and the strain of $\mathrm{Y}$ has a repetitive 
change trend of increasing and decreasing,, as shown in Fig. 5 (b) and (c). For progressive wave loading, the strain of $\mathrm{X}$ and $\mathrm{Y}$ shows the same trend of increasing first and then decreasing, but the temperatures corresponding to different progressive wave incidence angles are inconsistent. And the temperatures corresponding to the peaks of the $\mathrm{X}$ strain of progressive wave $0^{\circ}, 45^{\circ}, 90^{\circ}$ are $150^{\circ} \mathrm{C}, 200{ }^{\circ} \mathrm{C}$ and $200^{\circ} \mathrm{C}$, respectively, and the $\mathrm{Y}$ strain peak corresponds to $100^{\circ} \mathrm{C}$, as shown in Fig. 6-8(b) and (c). Analysis shows that for diffusion field the strain response of structure is more sensitive to temperature; for progressive wave loads, near the buckling area the Y strain of structure in is much higher than the $\mathrm{X}$ strain, leading the stress response to be mainly dominated by the $Y$ strain, as shown in Fig. 6-8 (a) and (c). Namely, for the progressive wave loads with a certain angle of incidence, in post-buckling the structure enters the snap-through area directly stoking the strain response with a certain direction, which will be the main influence factor of the stress response. However, for diffusion field loads without a certain angle of incidence, the stress response of structure will be effected jointly by the strain response of different directions.

\section{VERIFICATION}

For the validation of fundamental frequency in different temperatures, as shown in Table III. It can be seen that the simulation values has a pretty fine alignment with the test results, and also verify the modal change rule of structure in pre-buckling and post-buckling. Meanwhile, considering the actual patch position size of GH188 test pieces, extract the strain values of corresponding position in the simulation calculation, namely extract two units corresponding each patch the position, and select a more reasonable unit results to be compared with the test results. As a result of the structural response symmetry, only to select a value of $\mathrm{X}$ direction and $\mathrm{Y}$ direction in contrast analysis process, as shown in Table IV. Analysis shows that: the strain of $\mathrm{X}$ in simulation test has a good alignment to strain of $\mathrm{X}$ obtained by the diffusion field loading, the strain of $\mathrm{Y}$ in simulation test has a good alignment to strain of $\mathrm{Y}$ obtained by progressive wave $90^{\circ}$.

\section{CONCLUSIONS}

With the increase of progressive wave incident angle $\left(0^{\circ}-45^{\circ}-90^{\circ}\right)$, the Von Mises stress of structure gradually strengthens, and the results of progressive wave incident angle $0^{\circ}$ and $90^{\circ}$ are respectively the minimum and the maximum values of structural response. In diffusion field loading, the Von Mises stress of structure is among the results of progressive wave loads. For different acoustic loading ways, with the increase of the SPL the stress/strain response of structure has a change trend of approximately linear increasing first and then parabolic rising.

The stress response of the structure has a strong sensitivity to the acoustic loading ways. Namely, with a certain acoustic loading direction, near the buckling, the structure will be in a snap-through area, presenting the maximum stress response. However, for diffusion field without a certain acoustic loading direction, while the structure enters snap-through area, the peak stress response has a shift. For diffusion field the strain response of structure is more sensitive to temperature; for progressive wave loading near the buckling area the $\mathrm{Y}$ strain of structure in is much higher than the $\mathrm{X}$ strain, leading the stress response to be mainly dominated by the Y strain, Namely, for the progressive wave loads with a certain angle of incidence, in post-buckling the structure enters the snap-through area directly stoking the strain response with a certain direction, which will be the main influence factor of the stress response. However, for diffusion field loads without a certain angle of incidence, the strain response' function to stress response is uncertain.

\section{REFERENCE}

[1] N. C. Fai, "Nonlinear and snap-through responses of curved panels to intense acoustic excitation," Journal of Aircraft, vol. 26, pp. 281-288, 1989.

[2] C. Mei, J. M. Dhainaut, B. Duan, S. M. Spottswood, and H. F. Wolfe, "Nonlinear random response of composite panels in an elevated thermal environment," 2000.

[3] J. M. Dhainaut, X. Guo, C. Mei, S. M. Spottswood, and H. F. Wolfe, "Nonlinear random response of panels in an elevated thermal-acoustic environment," Journal of Aircraft, vol. 40, no. 4, pp. 683-691, 2003.

[4] S. A. Rizzi, "Experimental research activities in dynamic response and sonic fatigue of hypersonic vehicle structures at NASA Langley Research Center," AIAA, in Proc. 31st Aerospace Sciences Meeting and Exhibit, 1993, vol. 1, no. 12.

[5] C. F. $\mathrm{Ng}$ and S. A. Clevenson, "High-intensity acoustic tests of a thermally stressed plate," Journal of Aircraft, vol. 28, no. 4, pp. 275-281, 1991.

[6] N. C. Fai, "Design guide for predicting nonlinear random response(including snap-through) of buckled plates," 1989.

[7] N. C. Fai and K. R. Wentz, "The prediction and measurement of thermo-acoustic response of plate structures," presented at 31th AIAA/ASME/ASCE/AHS/ASC Structures, structural Dynamics, and Materials Conference, 1990.

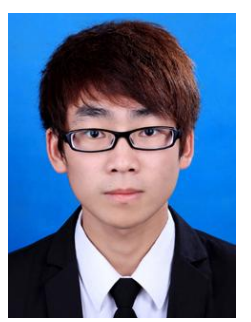

Wang Jian was born in Sichuan province, China He received her B.S. degree in process equipment and control engineering from Liaoning University of Petroleum and Chemical Technology.

$\mathrm{He}$ is currently a PhD Student in aeronautical and astronautical engineering at Shenyang Aerospace University. Mr. Wang's research interests include intensity, vibration and noise in airspace engines. 